\title{
Nutritional Control of Cellular Morphology in an Aerobic Actinomycete from the Hamster
}

\author{
BY H. V. JORDAN AND A. HOWELL, Jun. \\ U.S. Department of Health, Education, and Welfare, Public Health Service, \\ National Institutes of Health, National Institute of Dental Research, \\ Bethesda, Maryland 20014, U.S.A.
}

(Received 18 August 1964)

\section{SUMMARY}

An aerobic actinomycete isolated from a type of periodontal disease in hamsters showed a characteristic filament/diphtheroid dimorphism. Incubation under carbon dioxide favoured development of the diphtheroid form, whereas aerobic incubation favoured the mycelial form. Iron depletion also induced filament formation. Although magnesium concentration directly affected the rate and amount of growth, no effect on morphology was observed. Critical concentrations of streptomycin sulphate and chloramphenicol also induced mycelium formation.

\section{INTRODUCTION}

The aetiological relationship of an aerobic filamentous organism to a type of periodontal disease in hamsters was recently reported (Jordan \& Keyes, 1963; Keyes \& Jordan, 1964; Jordan \& Keyes, 1964). The morphology and physiology of this organism were described in detail (Howell, 1963; Howell \& Jordan, 1963) and its inclusion in the family Actinomycetaceae suggested. The tendency of the filaments to be replaced by diphtheroid organisms under certain cultural conditions was noted. Hurst (1950) had previously described this change of morphology in a similar organism from the hamster. Diphtheroid formation by Actinomyces bovis was also reported by Pine, Howell \& Watson (1960). Preliminary observations led us to believe that certain growth conditions might regulate these changes in morphology. For example, aerobic incubation seemed to favour the filamentous stage of growth. In the present work we have tested further the effects of the atmosphere of incubation as well as the influence of metals and antibiotics on the diphtheroid/ filament dimorphism of this actinomycete.

\section{METHODS}

The inoculum was derived from strains which had been serially transferred in Trypticase Soy broth (Baltimore Biological Laboratories, Baltimore, Md.) and incubated at $37^{\circ}$ in 'sealed' tubes in an atmosphere of $\mathrm{CO}_{2}$ produced from $10 \%$ (w/v) $\mathrm{Na}_{2} \mathrm{CO}_{3}+\mathrm{M}-\mathrm{KH}_{2} \mathrm{PO}_{4}$ (Pine \& Howell, 1956). This was to ensure that the inoculum would be essentially in the diphtheroid stage at the start of all experiments. The only exception to this was in experiments comparing the effect of atmosphere of incubation or to determine the effects of certain metals on morphological 
changes. In these cases, the inoculum was grown in Trypticase Soy broth incubated either aerobically or under $10 \%(\mathrm{w} / \mathrm{v}) \mathrm{Na}_{2} \mathrm{CO}_{3}+\mathrm{M}-\mathrm{KH}_{2} \mathrm{PO}_{4}$ 'seals'. Incubation was at $37^{\circ}$ in all experiments.

To determine the effect of atmosphere of incubation upon cellular and colony morphology, a direct comparison was made of the growth of 6 strains grown aerobically and under an atmosphere of $5 \% \mathrm{CO}_{2}+95 \% \mathrm{~N}_{2}(\mathrm{v} / \mathrm{v})$. Streak plates were prepared on brain heart infusion agar (Difco Laboratories, Detroit, Michigan) with one loopful of a 24-48 hr Trypticase Soy broth culture. Identical plates were incubated at $37^{\circ}$ in air and under an atmosphere of $5 \% \mathrm{CO}_{2}+95 \% \mathrm{~N}_{2}(\mathrm{v} / \mathrm{v})$. These were examined for cellular and colonial morphology under $\times 100$ and $\times 980$ magnification after 16-24 $\mathrm{hr}$ incubation.

In a separate experiment growth of 3 strains was compared by incubation in air, $5 \% \mathrm{CO}_{2}+95 \% \mathrm{~N}_{2}(\mathrm{v} / \mathrm{v})$ and also in an atmosphere of $\mathrm{CO}_{2}$-free nitrogen.

The effects of certain metals on the growth and morphology of two strains of this organism were determined in a Casitone + yeast extract medium (Medium I), incubated with $\mathrm{CO}_{2}$ 'seals' as used in previous studies (Howell \& Jordan, 1963).

Each of the metals normally added to the medium (g./l.: $\mathrm{MgSO}_{4} .7 \mathrm{H}_{2} \mathrm{O}, 0.2$; $\mathrm{CaCl}_{2} .2 \mathrm{H}_{2} \mathrm{O}, 0.02 ; \mathrm{FeSO}_{4} .7 \mathrm{H}_{2} \mathrm{O}, 0.04 ; \mathrm{MnSO}_{4} \cdot 2 \mathrm{H}_{2} \mathrm{O}, 0.0015 ; \mathrm{NaMoO}_{4} \cdot 2 \mathrm{H}_{2} \mathrm{O}$, 0.0015 ) was omitted separately to observe any change in growth or morphology due to metal deprivation. One loopful from a culture grown in Medium I with decreasing concentrations of magnesium (0.200 g./l. down to none added) was plated on the same medium containing $1.5 \%$ washed Noble's agar (Difco Laboratories). In similar experiments the various other metals were separately omitted. The plates were incubated at $37^{\circ}$ in an atmosphere of $5 \% \mathrm{CO}_{2}+95 \% \mathrm{~N}_{2}(\mathrm{v} / \mathrm{v})$. It was considered beyond the scope of these experiments to do any further metal purification of the medium itself.

A possible influence of sub-inhibitory concentrations of antibiotics on the dimorphism of this organism was also considered. One strain ( $\mathrm{T}$ 6) was first exposed to a range of concentrations of sodium penicillin $\mathrm{G}$, bacitracin, chloramphenicol and streptomycin sulphate in Trypticase Soy broth incubated under $\mathrm{CO}_{2}$ 'seals', to establish inhibitory concentrations for each antibiotic. The organism was then exposed to a narrow range of concentrations where growth would occur but where the morphology of the organisms might be influenced. Streak plates of Trypticase Soy agar containing appropriate concentrations of the antibiotic were incubated under $5 \% \mathrm{CO}_{2}+95 \% \mathrm{~N}_{2}(\mathrm{v} / \mathrm{v})$. These concentrations were as follows: sodium penicillin G, 0.01-0.1 units $/ \mathrm{ml}$; bacitracin, 0.2-1.5 units $/ \mathrm{ml}$; chloramphenicol, $0 \cdot 2-0.75 \mu \mathrm{g} . / \mathrm{ml}$. (w/v); streptomycin sulphate, $1 \cdot 0-10 \cdot 0 \mu \mathrm{g} . / \mathrm{ml}$. (w/v). Microcolonies on the plates were examined at $\times 100$ and $\times 980$ magnifications at intervals from 16 to $96 \mathrm{hr}$.

\section{RESULTS}

The atmosphere of incubation had a marked effect on cellular and colony morphology. Smooth cultures of 5 of 6 strains (and one of these in repeated experiments) on plates incubated under nitrogen + carbon dioxide continued to develop diphtheroid micro-colonies (Pl. 1, fig. 1) or micro-colonies bearing a short, refractile mycelial fringe with little or no branching, whereas those incubated in air reverted to branching mycelial micro-colonies (Pl. 1, fig. 2) so characteristic of these strains when first isolated from animals. The smooth cultures of three strains incubated 
under $\mathrm{CO}_{2}$-free nitrogen became predominantly filamentous, though occasional diphtheroid-like micro-colonies were found.

In contrast, filamentous cultures of one strain maintained by serial transfer in Trypticase Soy broth and incubated aerobically, continued to produce filamentous spider-like micro-colonies when inoculated on brain heart infusion plates, regardless of the atmosphere of incubation. Plates inoculated from initially filamentous cultures which had been carried by serial transfer in the Trypticase Soy broth with $\mathrm{KH}_{2} \mathrm{PO}_{4}+\mathrm{Na}_{2} \mathrm{CO}_{3}$ 'seals', however, invariably showed predominantly diphtheroid colonies when the plates were incubated under $\mathrm{CO}_{2}+\mathrm{N}_{2}$. Thus, it is obvious that increased $\mathrm{CO}_{2}$ tension was in large part responsible for the cultural dimorphism exhibited by these organisms.

In repeated experiments with strain $\mathrm{HS} 1$ and rough and smooth forms of strain T 6, when less than 50-70 mg. $\mathrm{MgSO}_{4} .7 \mathrm{H}_{2} \mathrm{O}$ were added per $\mathrm{l}$. Medium $\mathrm{I}$, both the rate and amount of growth were affected. Suboptimal concentrations had no effect upon cellular or colony morphology. Although the omission of iron, calcium, or manganese from Medium I did not influence significantly the rate or amount of growth, omission of iron, in some experiments, resulted in filamentous microcolonies (Pl. 1, fig. 3) in place of the diptheroid type found in controls (similar to Pl. 1, fig. 1). Omission of calcium or manganese had no effect on growth or morphology. Lack of consistency in these experiments with iron, and failure to find any effect of calcium or manganese may have been due to near adequate or adequate amounts of these elements already present in the medium.

Strain $\mathrm{T} 6$ used in the experiments in which antibiotics were incorporated in the medium was markedly sensitive to each of the four antibiotics tested. In addition, at a concentration of chloramphenicol $\mathbf{0 . 2} \mu \mathrm{g}$. $/ \mathrm{ml}$., only spider-like micro-colonies were observed after incubation for $66 \mathrm{hr}$ whereas control plates, after $16 \mathrm{hr}$ of incubation, showed predominantly diphtheroid colonies, or diphtheroid colonies bearing very short refractile filaments around the margin. Spider colonies were also found in plates containing chloramphenicol $\mathbf{0 . 3} \mu \mathrm{g} . / \mathrm{ml}$. after incubation for $90 \mathrm{hr}$. Low concentrations of sodium penicillin $G(0.05-0.075$ units $/ \mathrm{ml}$.) and bacitracin $(0 \cdot 6-1 \cdot 0$ units/ml.), although somewhat inhibitory, did not induce the formation of filamentous micro-colonies, but somewhat atypical heaped dense diphtheroid colonies were found after incubation for 40-90 hr. Filamentous colonies alone were produced on plates containing streptomycin sulphate $5 \mu \mathrm{g} . / \mathrm{ml}$ (Pl. 1, fig. 4) after $48 \mathrm{hr}$ incubation, whereas diphtheroid colonies alone were found on control plates. This effect of streptomycin on morphology was not found consistently in subsequent experiments.

\section{DISCUSSION}

Variations in the morphology of a variety of micro-organisms under the influence of different metabolic regulators have been described by numerous investigators. Winder \& Denneny (1959) reported that the growth of Mycobacterium smegmatis in a medium deficient in iron and zinc resulted in elongated filament-like organisms containing a low concentration of deoxyribonucleic acid as compared with normal organisms of the same age. In Nocardia opaca a manganese deficiency caused a marked filamentous growth and failure to fragment (Webley, 1960). Filamentous forms of Escherichia coli were observed by Ratledge \& Winder (1964) when this 
organism grew in an iron or zinc deficient medium. The tendency of Gram-positive bacteria to grow as long filaments under conditions of magnesium deficiency was described by Webb (1953). Although magnesium was required for growth of the ' hamster organism' in a medium containing other metals, no effect on morphology was observed. The addition of certain amino acids and other organic acids to a basal medium which supported growth of coccoid forms only of Arthrobacter crystallapoietus resulted in the formation of rod forms (Ensign \& Wolfe, 1964).

Similar effects may result from exposure to bacterial inhibitors. Elongated forms of Escherichia coli and Bacillus subtilis induced by penicillin were described by Pratt \& Dufrenoy (1948). The same effect was obtained by the use of sulphonamides and bacitracin. Fleming, Voureka, Kramer \& Hughes (1950) reported very long filaments and bizarre branching by Salmonella typhi, Vibrio cholerae, Pseudomonas pyocyanea, and Escherichia coli in the presence of sub-inhibitory concentrations of penicillin.

Carbon dioxide has been shown to exert a controlling influence on the morphology of Coccidiodies immitis (Lones \& Peacock, 1960), Sporotrichum schencki (Drouhet \& Mariat, 1952) and Histoplasma farciminosum (Bullen, 1949). Of additional interest in this respect is a report by Chan (1964) of aberrant forms of Arthrobacter globiformis induced by a biotin deficiency. Nickerson \& Mankowski (1953) reported that Candida albicans was maintained in the yeast phase in a simplified basal medium containing glucose and biotin.

Regulation of mould/yeast dimorphism of Mucor rouxii by adjustment of the carbon dioxide and oxygen tensions of the growth atmosphere was discussed by Bartnicki-Garcia (1963). The hypothesis was advanced that carbon dioxide fixation proceeds through the well-known malate pathway leading to aspartate formation. This may stimulate the formation and accumulation of mannan-protein in the cell wall of the yeast form. The inhibitory effect of oxygen on development of the yeast form was explained on the basis that under aerobic growth conditions operation 'of the tricarboxylic acid cycle may prevent any excessive accumulation of carboxylic acids resulting from $\mathrm{CO}_{2}$ fixation'.

Thus it is obvious that the factors which were shown to influence the morphology of our actinomycete have been adequately demonstrated to exert their morphogenic effects on a variety of other microbial forms. Demonstration of a nutritional control of morphology in cultures of an actinomycete raises questions about the relationship of various filamentous and diphtheroid organisms commonly described from the oral cavity, particularly in surveys which are based on visual examination of dental plaque material. Hurst (1950) pointed out the difficulties of a quantitative estimation of actinomycetes from tooth scrapings, based on morphology alone. The confusion surrounding the true identity of oral 'diphtheroids' which have been described in the literature was also mentioned by Morris (1954). Our work illustrates the fact that the morphology of these organisms in vivo can be significantly different from their appearance as cultivated in vitro. It is possible that the relatively high concentrations of available $\mathrm{CO}_{2}$ in the oral cavity would favour the diphtheroidal form of the organism.

The technical assistance of Mrs Norma Hartke and Mr W. Preston is gratefully acknowledged. 


\section{REFERENCES}

Bartnicki-García, S. (1963). Symposium on biochemical bases of morphogenesis in fungi. III. Mold-yeast dimorphism of Mucor. Bact. Rev. 27, 293.

Bullen, J. J. (1949). The yeast-like form of Cryptococcus farciminosus (Rivolta): Histoplasma farciminosum. J. Path. Bact. 61, 117.

Chan, E. C. S. (1964). Morphological aberration of Arthrobacter globiformis cells due to biotin deficiency. J. Bact. 87, 641.

Drouhet, E. \& Mariat, F. (1952). Etude des facteurs déterminant le développement de la phase levure de Sporotrichum schencki. Annls Inst. Pasteur, Paris, 83, 506.

Ensign, J. C. \& Wolfe, R. S. (1964). Nutritional control of morphogenesis in Arthrobacter crystallopoietes. J. Bact. 87, 924.

Fleming, A., Voureka, A., Kramer, I. R. H. \& Hughes, W. H. (1950). The morphology and motility of Proteus vulgaris and other organisms cultured in the presence of penicillin. J. gen. Microbiol. 4, 257.

Howell, Jr., A. (1963). A filamentous micro-organism isolated from periodontal plaque in hamsters. I. Isolation, morphology, and general cultural characteristics. Sabouraudia, $3,81$.

Howell, Jr., A. \& Jordan, H. V. (1963). A filamentous micro-organism isolated from periodontal plaque in hamsters. II. Physiological and biochemical characteristics. Sabouraudia, 3, 93.

Hurst, V. (1950). Morphologic instability of actinomycetes associated with enamel. J. dent. Res. 29, 571.

JoRDAN, H. V. \& Keyes, P. H. (1963). Induction of subgingival plaque and periodontal pathosis in hamsters by a Gram-positive filamentous organism. Proc. int. Assn dent. Res. Abstract No. 319, p. 115.

Jordan, H. V. \& Keyes, P. H. (1964). Aerobic, gram-positive, filamentous bacteria as etiologic agents of experimental periodontal disease in hamsters. Arch. oral Biol. 9. 401.

Keyes, P. H. \& Jordan, H. V. (1964). Periodontal lesions in the Syrian hamster. III. Findings related to an infectious and transmissible component. Arch. oral Biol. 9. 377.

Lones, G. W. \& Peacock, C. L. (1960). Role of carbon dioxide in the dimorphism of Coccidioides immitis. J. Bact. 79, 308.

Morris, E. O. (1954). The bacteriology of the oral cavity. V. Cornynebacterium and grampositive filamentous organisms. Brit. dent. J. 97, 29.

Nickerson, W. J. \& Mankowski, Z. (1953). Role of nutrition in the maintenance of the yeast-shape in Candida. Amer. J. Bot. 40, 584.

Pine, L. \& Howell, Jr., A. (1956). Comparison of physiological and biochemical characters of Actinomyces spp. with those of Lactobacillus bifidus. J. gen. Microbiol. 15, 428.

Pine, L., Howelx, Jr., A. \& WATson, S. J. (1960). Studies of the morphological, physiological, and biochemical characters of Actinomyces bovis. J. gen. Microbiol. 23, 403.

Pratt, R. \& Dufrenoy, J. (1948). Cytochemical interpretation of the mechanism of penicillin action. Bact. Rev. 12, 79.

RAtledge, C. \& Winder, F. G. (1964). Effect of iron and zine on growth patterns of Escherichia coli in an iron-deficient medium. J. Bact. 87, 823.

WEBв, M. (1953). Effects of magnesium on cellular division in bacteria. Science, 118, 607 .

WEBLEY, D. M. (1960). The effect of deficiency of iron, zinc, and manganese on the growth and morphology of Nocardia opaca. J. gen. Microbiol. 23, 87.

Winder, F. \& Denneny, J. M. (1959). Effect of iron and zinc on nucleic acid and protein synthesis in Mycobacterium smegmatis. Nature, Lond. 184, 742. 


\section{EXPLANATION OF PLATE}

\section{Prate 1}

Fig. 1. Micro-colonies of actinomycete strain $\mathbf{T} 6$, on brain heart infusion agar incubated for $16 \mathrm{hr}$ at $37^{\circ}$ in $5 \% \mathrm{CO}_{2}+95 \% \mathrm{~N}_{2}(\mathrm{v} / \mathrm{v}) . \times 440$.

Fig. 2. Micro-colonies of actinomycete strain $\mathrm{T}$ 6, on brain heart infusion agar incubated for $24 \mathrm{hr}$ at $37^{\circ}$ in air. $\times 440$.

Fig. 3. Micro-colonies of actinomycete strain $\mathbf{T} 6$, on medium $I$, containing $1.5 \%(w / v)$ washed Noble's agar without added iron. Incubated for $20 \mathrm{hr}$ at $37^{\circ}$ in $5 \% \mathrm{CO}_{2}+95 \% \mathrm{~N}_{2}(\mathrm{v} / \mathrm{v}) . \quad \times 440$. Fig. 4. Micro-colonies of actinomycete strain $\mathbf{x} 6$, on Trypticase Soy agar containing streptomycin sulphate $5 \mu \mathrm{g} . / \mathrm{ml}$; incubated for $48 \mathrm{hr}$ at $37^{\circ}$ under $5 \% \mathrm{CO}_{2}+95 \% \mathrm{~N}_{2}(\mathrm{v} / \mathrm{v}) . \quad \times 440$. 


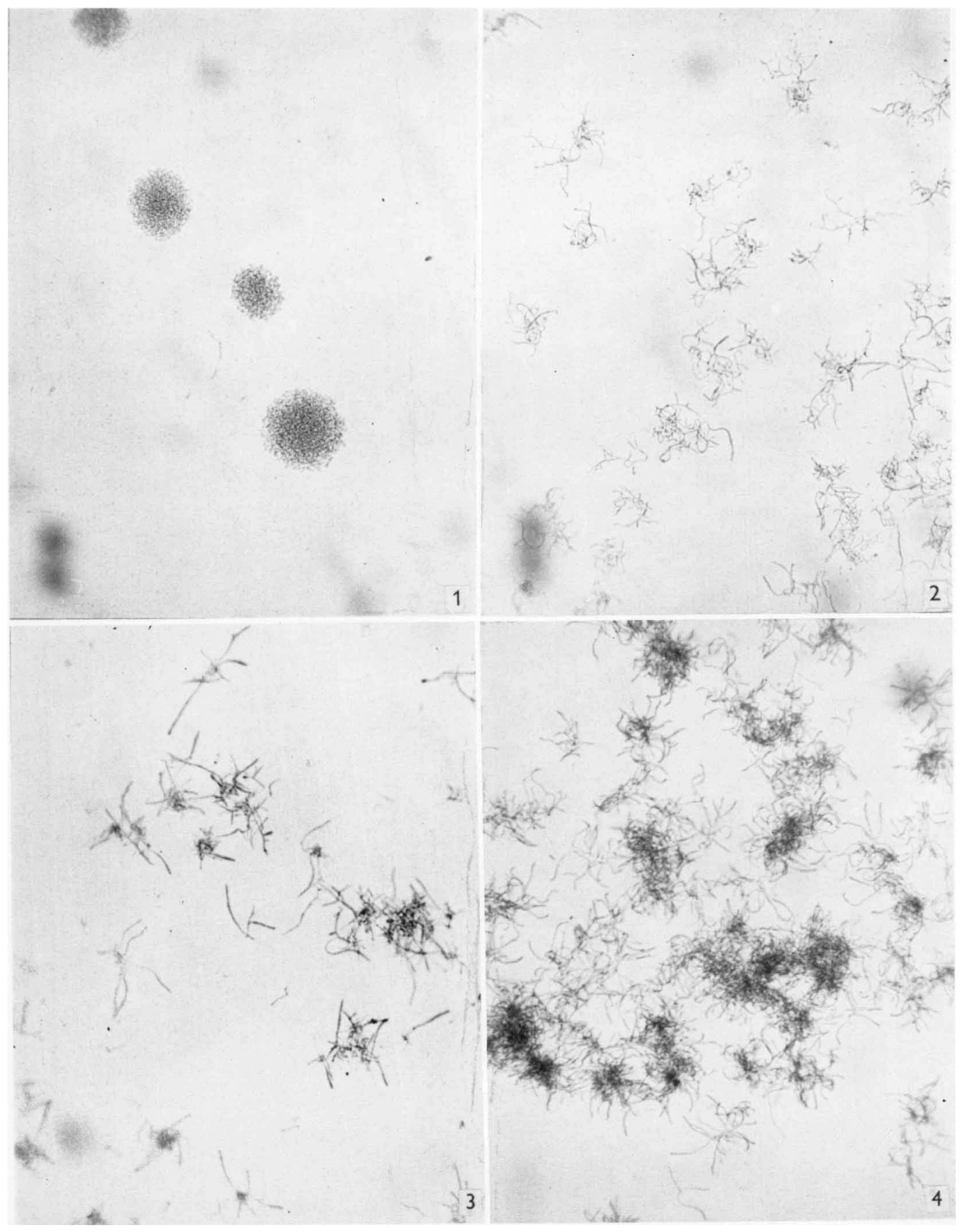


